Published in final edited form as:

J Phys Chem B. 2005 February 10; 109(5): 1669-1674.

\title{
Enhancing the Photoluminescence of Peptide-Coated Nanocrystals with Shell Composition and UV Irradiation
}

\author{
James M. Tsay ${ }^{\dagger}$, Sören Doose ${ }^{\dagger}, \S$, Fabien Pinaud ${ }^{\dagger}$, and Shimon Weiss ${ }^{*}, \dagger, \ddagger$ \\ Department of Chemistry and Biochemistry, and Department of Physiology, University of California at Los \\ Angeles, Los Angeles, California 90095
}

\begin{abstract}
The composition and structure of inorganic shells grown over CdSe semiconductor nanocrystal dots and rods were optimized to yield enhanced photoluminescence properties after ligand exchange followed by coating with phytochelatin-related peptides. We show that, in addition to the peptides imparting superior colloidal properties and providing biofunctionality in a single-step reaction, the improved shells and pretreatment with UV irradiation resulted in high quantum yields for the nanocrystals in water. Moreover, peptide coating caused a noticeable red-shift in the absorption and emission spectra for one of the tested shells, suggesting that exciton-molecular orbital (X-MO) coupling might take place in these hybrid inorganic-organic composite materials.
\end{abstract}

\section{Introduction}

Core/shell nanocrystals ( $\mathrm{NCs}$ ) such as $\mathrm{CdSe} / \mathrm{ZnS}$ are nanometer scale inorganic clusters of semiconductor material useful for fluorescent labeling in multicolor biological imaging and detection. 1,2 These colloidal NCs consist of an inorganic particle and an organic coating that determines their solubility and functionality and influences their photophysics. For these NCs to be biocompatible, they must be water-soluble, be nontoxic to the cell, and offer conjugation chemistries for attaching recognition molecules to their surfaces. In addition, they should efficiently target to biomolecules of interest, be chemically stable, and preserve their high photostability. The requirements for their application in single-molecule biological studies are even more stringent: fluorescent NCs should be monodisperse and have relatively small size (to limit steric hindrance), reduced blinking, large saturation intensity, and high quantum yield (QY).

Two coating steps are necessary to render CdSe NCs synthesized in organic solvents highly luminescent, water-soluble, and biocompatible. The first coating step is the chemical deposition of higher band-gap inorganic shells over NC cores. ${ }^{3-6}$ These shells serve as isolation layers, protecting the exciton wave function from nonradiative recombination processes at surface traps. The second coating step permits the functionalization of the NCs. Various coating chemistries have been described: silanization, ${ }^{7,8}$ mercaptoalkanoic acid ligands, ${ }^{9}$ organic dendrons, ${ }^{10}$ amphiphilic polymers, ${ }^{11}$ phospholipid micelles, ${ }^{12}$ recombinant proteins, ${ }^{13}$ and oligomeric phosphines. ${ }^{14}$ The fact that several different coatings have continuously been introduced points to the difficulty in achieving all desired properties with one universal coating. It implies that different coatings will most likely be necessary for various

\footnotetext{
* Corresponding author. E-mail: sweiss@ chem.ucla.edu..

†Department of Chemistry and Biochemistry.

\$Department of Physiology.

§Current address: Applied Laserphysics and Laserspectroscopy, University of Bielefeld, 33615 Bielefeld, Germany.
}

Supporting Information Available: NC absorption/emission spectroscopy, and TEM, FCS, and TIR data. This material is available free of charge via the Internet at http://pubs.acs.org. 
applications. NCs with thicker coatings will tend to have better photo-stabilities and higher quantum yields, whereas smaller NCs with thin coatings may be less photostable but will be better suited as intracellular probes.

We have recently reported the coating of $\mathrm{CdSe} / \mathrm{ZnS}$ core/shell NCs with phytochelatin-related peptides, leading to bioactive NCs having only a thin water-soluble shell. ${ }^{15}$ Peptide coating endows the NCs with exceptional colloidal properties as proven by HPLC, gel electrophoresis, atomic force microscopy (AFM), transmission electron microscopy (TEM), and fluorescence antibunching studies. ${ }^{16}$ These peptides have a C-terminal adhesive hydrophobic domain with multiple cysteinyl thiolate binding sites and a hydrophilic domain which gives the NCs their desired solubility and functionality. However, this previously reported biofunctionalization scheme significantly reduced the NC's QY in aqueous buffer.

Deposition of a ZnS shell for the first coating step was initially chosen because it offered exceptional photostability for CdSe NCs. However, decreases in QY of CdSe NCs with increasing shell thickness are often observed because of the large lattice mismatch (12\%) between core and shell. ${ }^{5}$ To decrease this lattice mismatch, Manna and co-workers grew CdS/ $\mathrm{ZnS}$ graded shells over CdSe nanorods and demonstrated large increases in QY and high photostability after laser annealing. ${ }^{17}$ We initially hypothesized that growing larger shells with cadmium dopants would prevent the core exciton from interacting with the environment, thus allowing less nonradiative relaxation and higher quantum yield. However, we observed that such shells may actually allow the exciton to interact with the molecular orbitals of the peptides used in this study. By reducing the shell band-gap offset, and/or by introducing low-lying (mid gap) level dopants into the shell, the excitonic wave function could be made to leak further out of the core, affording such exciton (X)-molecular orbital (MO) interactions (X-MO interactions) that may give more favorable effects on the photoluminescence than a higher band-gap shell (ZnS).

To characterize the effects of shell composition and structure as well as UV irradiation on the fluorescence of NCs synthesized in this study, we used ensemble UV/vis absorption and photoluminescence emission spectroscopy. Fluorescence correlation spectroscopy was also employed to study the nature of quantum yield increases of peptide-coated NCs with UV irradiation.

\section{Experimental Section}

\section{Samples.}

We studied four different shell compositions grown over spherical NCs cores (Table 1). One of the shells was also grown over nanorods: (\#1) 4-5 monolayers of $\mathrm{ZnS}$ shell grown over 4.5 $\mathrm{nm} \mathrm{CdSe}$ cores; (\#2) 4-5 monolayers of CdS/ZnS graded shell grown over $4.5 \mathrm{~nm}$ CdSe cores; (\#3) 1-2 monolayers of CdS followed by 3-4 monolayers of ZnS layered shells grown over $4.5 \mathrm{~nm}$ CdSe cores; (\#4) 5 monolayers of CdS shell grown over $3.5 \mathrm{~nm}$ CdSe cores; and (\#5) $4-5$ monolayers of $\mathrm{CdS} / \mathrm{ZnS}$ graded shell grown over $\sim 5 \times 25 \mathrm{~nm}$ CdSe nanorods.

\section{Materials/Chemicals.}

Dimethylcadmium $\left(\mathrm{Cd}\left(\mathrm{CH}_{3}\right)_{2}, 97 \%\right)$ and tri- $n$-butylphosphine (TBP, 99\%) were purchased from Strem (Newburyport, MA). Cadmium oxide, diethylzinc $\left(\mathrm{C}_{4} \mathrm{H}_{10}-\mathrm{Zn}, 1.0 \mathrm{M}\right.$ solution in heptane), and hexamethyldisilthiane $\left(\mathrm{C}_{6} \mathrm{H}_{18} \mathrm{Si}_{2} \mathrm{~S}\right.$ or $\left.\mathrm{TMS}_{2} \mathrm{~S}\right)$ were purchased from Aldrich (Milwaukee, WI). Hexylphosphonic acid, tetradecylphosphonic acid, and trioctylphosphine oxide (TOPO, Tech) were purchased from Alfa Aesar (Ward Hill, MA). Peptides were purchased from Synpep with at least $80 \%$ purity. 


\title{
CdSe Quantum Dot and Nanorod Core Synthesis.
}

Quantum dot cores were synthesized by using similar methods developed by Murray et al. ${ }^{18}$ The precursor solution was prepared in a glovebox where selenium powder $(0.149 \mathrm{~g})$ and tributylphosphine (1.48 g) were mixed until the selenium dissolved. Dimethyl cadmium (0.36 $\mathrm{g})$ as well as an additional amount of tributylphosphine $(8 \mathrm{~g})$ were added to the solution. In a $100 \mathrm{~mL}$ round-bottomed flask, TOPO $(8 \mathrm{~g}$, Technical grade $)$ was heated to $120^{\circ} \mathrm{C}$ under nitrogen flow. The flask was purged under vacuum for $30 \mathrm{~min}$ and two more times for $5 \mathrm{~min}$ each. The temperature was raised to $360{ }^{\circ} \mathrm{C}$, and $2.5 \mathrm{~mL}$ of the precursor solution was injected quickly. After injection, the temperature was quickly adjusted to $300^{\circ} \mathrm{C}$ for growth. To increase the size of the NCs and prevent Ostwald ripening, additional injections of $1 \mathrm{~mL}$ of the stock solution were added every 30 min until the desired size was reached. The solution was cooled to $40{ }^{\circ} \mathrm{C}$, and methanol was used to precipitate the nanocrystals. Nanorod cores were synthesized by using the two-pot method with aged Cd-TDPA complexes established by Peng et al. ${ }^{19}$

\section{Shell Synthesis.}

$\mathrm{ZnS}$ shells were grown over CdSe cores according to Hines et al. ${ }^{4}$ with the following modifications. First, $10-40 \mathrm{mg}$ of precipitated cores was redispersed in $0.5 \mathrm{~mL}$ of chloroform or toluene. A solution containing TBP (8.26 g), diethylzinc (1.26 g), hexamethyldisilithiane $(0.304 \mathrm{~g})$, and optionally dimethyl cadmium was prepared in a glovebox and stored under nitrogen at $-20{ }^{\circ} \mathrm{C}$. A solution of trioctylphosphine oxide (TOPO) $(4 \mathrm{~g}, 99 \%)$ was heated to $100{ }^{\circ} \mathrm{C}$ and purged for $30 \mathrm{~min}$ under vacuum. This was repeated twice for $5 \mathrm{~min}$ intervals. Tributylphosphine (TBP) $(0.5 \mathrm{~mL})$ was injected into the TOPO solution. The core solution was also injected into the solution at $100{ }^{\circ} \mathrm{C}$ and purged to evaporate chloroform and toluene. The reaction flask was filled with nitrogen and heated to $160^{\circ} \mathrm{C}$. The shell solution was injected at $\sim 0.1 \mathrm{~mL} / \mathrm{min}$. For formation of $\mathrm{CdS} / \mathrm{ZnS}$ shells, the cadmium precursors were injected with the zinc precursors, and for the successive layers of $\mathrm{CdS}$ shell and $\mathrm{ZnS}$ shell, the cadmium and sulfur precursors were injected before the zinc and sulfur precursors. After the shell precursor addition was completed, the reaction flask was left at $160{ }^{\circ} \mathrm{C}$ for $10 \mathrm{~min}$ and then cooled at 90 ${ }^{\circ} \mathrm{C}$ for $30 \mathrm{~min}$ and further cooled to $40^{\circ} \mathrm{C}$, at which point $2-3 \mathrm{~mL}$ of butanol $(99.99 \%$ ) was added. $\mathrm{CdSe} / \mathrm{CdS}$ core/shell NCs were synthesized via the successive ion layer adsoprtion and reaction (SILAR) method. ${ }^{20}$ The shell synthesis and laser annealing used for CdSe/CdS/ZnS nanorods were performed using the protocol by Manna et al. ${ }^{17}$

\section{Peptide Coating.}

A detailed procedure and schematic of peptide coating are found in ref ${ }^{15}$. The following peptides were used to overcoat the NCs synthesized in this study:

\author{
G-S-E-S-G-G-S-E-S-G-Cha-C-C-Cha-C-C-Cha-C-C-Cha-cmd \\ suc-G-S-S-S-G-G-S-S-S-G-Cha-C-C-Cha-C-C-Cha-C-C-Cha-cmd \\ K-G-S-E-S-G-G-S-E-S-G-Cha-C-C-Cha-C-C-Cha-C-C-Cha-cmd \\ Biotin-G-S-E-S-G-G-S-E-S-G-Cha-C-C-Cha-C-C-Cha-C-C-Cha-cmd \\ PEG-Cha-C-C-Cha-C-C-Cha-C-C-Cha-cmd
}

Briefly, TOPO-coated core/shell NCs were precipitated with methanol and redissolved in pyridine to a concentration of $1 \mu \mathrm{M}$. An excess of peptides, typically $4.0 \mathrm{mg}$ in $50 \mu \mathrm{L}$ of DMSO, was then mixed with $450 \mu \mathrm{L}$ of the NCs solution. The surfactant exchange and the binding of peptides on the NCs were triggered by the addition of $12 \mu \mathrm{L}$ of tetramethylammonium hydroxide (TMAOH) 25\% (w/v) in methanol. The mixture was then quickly vortexed and centrifuged. The NCs precipitate obtained was redissolved in DMSO and eluted through a G-25 
Sephadex desalting column (Amersham, Piscataway, NJ) equilibrated with water. The peptidecoated nanoparticles were then dialyzed against a PBS buffer $(50 \mathrm{mM} \mathrm{NaCl}, 10 \mathrm{mM}$

$\mathrm{Na}_{2} \mathrm{HPO}_{4}, \mathrm{pH}$ 7.2) to remove the excess of unbound peptides.

\section{Fluorescence Correlation Spectroscopy.}

Fluorescence correlation spectroscopy (FCS) measurements were performed using a confocal excitation/detection scheme. Laser excitation of a femtoliter volume in a sample solution was provided by a Nd:YAG laser at $532 \mathrm{~nm}$ (Crystal Laser Inc.) with $1.5 \mu \mathrm{W}$ excitation power (measured before the objective). Fluorescence was detected in epi-configuration on an inverted microscope (Axiovert 100, Zeiss Inc.). Using a nonpolarizing beam splitter, two avalanche photodiodes (AQR-13, Perkin-Elmer Inc.), and a hardware correlator (ALV, Germany), the cross-correlation was observed. Occupancy was acquired by taking the inverse of the correlation amplitude, and the brightness per particle was calculated by multiplying the occupancy by the average count-rate during data acquisition.

\section{Phototreatment.}

Graded shell $\mathrm{CdSe} / \mathrm{CdS} / \mathrm{ZnS}$ nanorods were photoannealed for $2-4 \mathrm{~h}$ using $488 \mathrm{~nm}$ radiation from an argon ion laser at $25 \mathrm{~mW}$. All other samples were irradiated with UV light for $40 \mathrm{~min}$ to several hours using a $4 \mathrm{~W}$ UV lamp with $366 \mathrm{~nm}$ radiation.

\section{Quantum Yield Measurements.}

Quantum yields were acquired by exciting dye LD690 (63\% QY) and the NC sample at the same OD at $500 \mathrm{~nm}$, taking fluorescence spectra (corrected for detector efficiency), and comparing the integrated emission intensities.

\section{Inductively Coupled Plasma (ICP).}

Measurements were performed by Desert Analytics (Tucson, AZ).

\section{Results}

In this report, we studied the effects of both modifying the shell composition on CdSe cores and irradiating these NCs with UV light (Table 1) with ensemble absorption and emission spectroscopy. NC samples in Table 1 are a representative set of NCs synthesized for this study, with repeated measurements of QY after peptide coatings done at different times. We screened various compositions/structures of shells around CdSe cores and irradiated these NCs to find the most optimal conditions for high QY peptide-coated NCs. Three effects on the final QYs of peptide-coated NC were found in this study: irradiation of core/shell NCs in toluene before peptide coating, prevention of photoluminescence quenching after peptide coating through appropriate choices of the inorganic shell, and a final UV irradiation treatment after peptide coating to further increase the photoluminescence.

Irradiation-driven effects on the QYs of NCs in toluene were as follows: the QY of graded shell $\mathrm{CdSe} / \mathrm{CdS} / \mathrm{ZnS}$ nanorods doubled from $8 \%$ to $16 \%$ after laser annealing, showing results similar to those of the previously reported laser annealing on $\mathrm{CdSe} / \mathrm{CdS} / \mathrm{ZnS}$ nanorods. ${ }^{17}$ Surprisingly, an increase of QY (from $1 \%$ to over 25\%) was observed for graded shell CdSe/ $\mathrm{CdS} / \mathrm{ZnS}$ quantum dots when left for several weeks to months in the dark in air, or in a much more accelerated fashion, after being exposed to UV illumination (Figure 1). On the other hand, UV irradiation of NCs while still in toluene did not significantly increase QYs of samples \#1 and \#4 (first column of Table 1).

The ensemble absorption/emission spectroscopy results, quantum yields and emission spectra before and after peptide exchange, are summarized in Figure 2 and Table 1. Differences in the 
QY losses for various shell compositions can be observed after peptide exchange on NCs. For the CdSe/ZnS NCs sample (shell composition \#1), QYs of 19\% (in toluene, before peptide exchange) and 9\% (in water, after peptide exchange) were measured, respectively. More typical QYs in water for other CdSe/ZnS samples with different core sizes were in the 1-2\% range, similar to results found in a previous study. ${ }^{15} \mathrm{The} \mathrm{CdSe} / \mathrm{CdS}$ (shell composition \#4) and CdSe/ $\mathrm{CdS} / \mathrm{ZnS}$ layered (shell composition \#2) samples also displayed low QY $(<10 \%)$ after peptide exchange. For graded shell CdSe/CdS/ZnS NCs (shell composition \#2), the measured QYs were $26 \%$ before peptide exchange and $23.5 \%$ after peptide exchange, showing only slight changes in brightness. For CdSe nanorods coated with a graded $\mathrm{CdS} / \mathrm{ZnS}$ shell (shell composition \#5), the measured QYs were 16\% before peptide exchange and 8-9\% after peptide exchange, showing a larger loss in QY than for QDs of the same composition.

To better characterize the fluorescence of the NCs synthesized in these studies in solution, we used fluorescence correlation spectroscopy (FCS). ${ }^{21,22}$ FCS was employed to study both the photophysical and the colloidal properties of the NCs concurrently (a detailed discussion on the utilization of FCS in the analysis of NCs will be published elsewhere ${ }^{23}$ ). Beyond providing an estimate of the diffusion constant and hydrodynamic radius, correlation curves also provide information on the average number of NCs occupying the confocal volume (i.e., occupancy or concentration). By normalizing the average count rate during the measurement to the occupancy, the brightness per particle (BPP) can be extracted. After peptide-coating, $\mathrm{CdSe} /$ $\mathrm{CdS} / \mathrm{ZnS}$ NCs (sample \#2) showed a BPP that is 40-50\% higher than that of CdSe/ZnS (sample \#1), which agrees with the higher QYs found for sample \#2 in ensemble measurements. No signs of aggregation for either sample were detected.

The mechanism behind photoinduced QY increases with UV irradiation on NCs was studied on the ensemble level (by absorption/emission spectroscopy) and at low concentrations using FCS. Whereas ensemble absorption spectroscopy is sensitive to all NCs that absorb light, FCS is only sensitive to photoactive NCs (in the "on" or "bright" state). QYs of both samples \#1 and \#2 increased with UV irradiation (Table 1). These ensemble results (Figure 1) were confirmed by FCS (Figure 3). BPP of peptide-coated CdSe/ZnS (sample \#1) increased through 40 min of UV irradiation with no appreciable change in concentration. In contrast, both the BPP and the concentration of particles with graded shells (sample \#2) were increased upon UV irradiation.

Finally, it can be seen in Table 1, Figure 2, and the Supporting Information that the shell composition has an effect on the final emission peak of the photoluminescence of peptide NCs. Considerable permanent red shifts in both the absorption and the emission peaks were observed for sample \#2 (5-10 nm) and sample \#5 (4-6 nm) after ligand exchange with peptides. Only small red shifts $(0-3 \mathrm{~nm})$ were observed for samples \#1, \#3, and \#4. The red shifts found for graded shell NCs occurred either immediately following the completion of the peptide coating or eventually after long periods of time (weeks to months).

\section{Discussion}

The observed large increases in QY of graded shell CdSe/CdS/ZnS NCs in toluene could be due to slow surface reconstruction (in the dark) of the shell, photoannealing of defects in the shell with both laser and UV irradiation, or a combination of the two. Because the QY of the graded shell CdSe/CdS/ZnS NCs increases slowly in the absence of strong irradiation, UV illumination may simply speed up surface reconstruction which would cause better passivation of defects on the surface. The results for QY increase of graded shell NCs in this study were similar to those found in a previous study where no photoluminescence peak shift was detected due to irradiation. ${ }^{17}$ This implies that oxidation of the core/shell interface would not be the cause of increasing photoluminescence. Therefore, annealing of defects in the shells is still a 
possible explanation. Because the CdSe/ZnS NCs did not increase QY significantly in toluene after irradiation, binary shells do not seem to be as easily photoannealed.

The varying results for QY changes after peptide coating for samples 1-5 show that the shell composition/structure is a major factor in the QY of peptide-coated NCs. In all cases besides $\mathrm{CdSe} / \mathrm{ZnS}$, QY and emission changes similar to those in Table 1 were acquired with cores of different sizes. Noting that coating core/shell NCs with thiol ligands usually lead to lower QY in water, Kim et al. used thin coats made of oligomeric phosphine ligands to bind to the surface of these NCs, producing water-soluble NCs with relatively high quantum yield. ${ }^{14}$ The rationale behind their method was that the oligomeric phosphine ligands passivate the surface of the NCs better than thiols. Here, we show that thiols do not necessarily cause a large decrease in quantum yield. Instead of optimizing ligands for better photo-luminescence properties, we have modified the shell composition and structure while using peptide ligands with the same hydrophobic binding domains. Sample \#2, with its graded shell, clearly has the smallest QY loss out of all NC samples studied.

The final step of photoluminescence enhancement of peptide-coated NCs uses UV illumination to recover any quenching effects due to peptide overcoating. Taking into account the FCS results in which there are differences in both BPP and occupancy (concentration) due to UV irradiation, it is likely that two mechanisms are responsible for QY changes in peptide-coated NCs: an increase in the intrinsic brightness of each NC and the activation of initially "dark" $\mathrm{NCs}$ to the "on" state. Evidence for "dark" NCs was recently reported using combined singlemolecule fluorescence/AFM techniques. ${ }^{24} \mathrm{We}$ also observed the photoactivation of core/shell NCs while imaging them by total internal reflection microscopy (Supporting Information S-5). According to the FCS results, UV illumination of graded shell CdSe/CdS/ZnS NCs increases the intrinsic brightness of each particle as well as photoactivates "dark" NCs to their "on" state. In contrast, UV illumination of peptide-coated CdSe/ZnS NCs increases only the intrinsic brightness of each particle but does not affect the concentration. The intrinsic brightness increases may possibly be due to less blinking. These results further explain why the final quantum yield of graded shell CdSe/CdS/ZnS NCs is higher than that of CdSe/ZnS NCs.

The red-shifting phenomenon after peptide coating of core/shell NCs has further implications. These shifts in the absorption and photoluminescence peaks occurred only after the NCs were coated with peptides at room temperature. TEM results show that the sizes of the NCs are the same before and after peptide exchange (ref 15 and Supporting Information S-4), making it extremely unlikely that Ostwald ripening could explain these effects. The shifts to lower energy therefore suggest that the exciton of the $\mathrm{CdSe} / \mathrm{CdS} / \mathrm{ZnS}$ NCs may interact with the MOs of the surface recognition domain in the peptide sequences. The broadening of the exciton peak in the absorption spectra, which is observed after peptide coating, in samples \#2 and \#5, also suggests a possible change in the interaction between excitonic states and the peptides. Talapin et al. have previously noticed a reversible shift in the emission peak of CdSe cores upon surface ligand exchange between TOPO and amines. ${ }^{25}$ They suggested that different passivating ligands redistribute electron density in the semiconductor. In the case of peptide-coated NCs, the peptide coating exchange may cause surface reconstruction on the shells of the NCs causing a similar wave function displacement. However, ligand exchange of graded shell CdSe/CdS/ $\mathrm{ZnS}$ NCs with different thiolated molecules such as dihydrolipoic acid (DHLA) or mercaptopropionic acid did not yield red-shifted emissions, providing further evidence that the red-shifted emission is not simply caused by thiol bonds, but is due to the particular properties of the peptides. Peptides with different functional hydrophilic domains but identical adhesive hydrophobic domains resulted in the same red shifts. This implies that the hydrophobic Cterminal adhesive domain is responsible for the shift. 
As was mentioned, the most noticeable red shifts were observed for NCs with cadmiumcontaining graded shells. The graded CdS/ZnS ternary shells have a lower band gap and band offsets as compared to $\mathrm{ZnS}$ binary shells. Alternatively, $\mathrm{Cd}$ could be considered as a dopant that introduces mid-gap energy states into the $\mathrm{ZnS}$ shell (Figure 4). In both cases, there is a higher probability that the electronic wave function would leak further out of the shell, permitting stronger interaction between the exciton and the surrounding environment of the NCs. Inductively coupled plasma (ICP) results verify the composition differences in the shells of samples 1-3. The amount of cadmium content in the shell of samples 2 and 3 was determined by using $\mathrm{CdSe} / \mathrm{ZnS}$ as a standard, assuming the cadmium-to-selenium ratio of the cores was the same in samples $1-3$, and subtracting the core cadmium and selenium amounts from the entire core/shell sample. The quantum yield and red-shifted photoluminescence peak differences after peptide exchange between NCs with layered and graded shells with similar CdS content (22\% layered, $15 \%$ graded) suggest that the structure of the shell may also play an important role in the interaction between the ligands and the nanocrystal.

In summary, in this study, we have found that samples \#2 and \#5 (graded shells) have optimal shell configurations and retain most of their initial QYs after peptide exchange. Furthermore, these samples are most responsive to QY enhancement with UV irradiation, which enables them to have the highest final QYs out of all of the NCs studied. Finally, these samples show the largest potential for interaction between the exciton wave function and the peptides as evidenced by their red-shifting photoluminescence and absorption peaks.

\section{Conclusions}

We demonstrated that water-soluble peptide-coated NCs with modified graded CdS/ZnS shells have high QY that could be further enhanced by UV irradiation. The irradiation increases both the intrinsic brightness per particle and the number of bright particles in the sample. The resulting NCs are small, monodisperse, bioactive, very photostable, and have high QY. The enhanced properties make these probes suitable for single-molecule experiments in live cells. 15 We also demonstrated water-soluble peptide-coated nanorods that could possibly be used as orientational probes for studying rotational movements of macromolecules. We hypothesize that exciton-molecular orbital coupling might play an important role in determining the photophysical properties of these hybrid inorganic-organic composite materials and that such coupling could be further exploited by screening libraries of shell compositions and peptide sequences.

\section{Acknowledgements}

We would like to thank J. Jack Li for TEM pictures and Xavier Michalet for helpful discussions. This work was supported via funding from the National Institute of Health, Grant No. 5-R01 EB000312-04, DARPA, and AFOSR, Grant No. FA955004-10048. S.D. was supported by the Boehringer Ingelheim Fonds. We would also like to acknowledge the W. M. Keck Foundation for their support to this work from the W. M. Keck Epithelial Cell Cancer Biology Program at UCLA (Grant \# 04074070). Fluorescence correlation spectroscopy was performed at the UCLA/ CNSI Advanced Light Microscopy/Spectroscopy Shared Facility.

\section{References}

1. Michalet X, Pinaud F, Lacoste TD, Dahan M, Bruchez MP, Alivisatos AP, Weiss S. Single Mol 2001;2:261.

2. Alivisatos AP. Nat. Biotechnol 2004;22:47. [PubMed: 14704706]

3. Peng X, Schlamp MC, Kadavanich AV, Alivisatos AP. J. Am. Chem. Soc 1997;119:7019.

4. Hines MA, Guyot-Sionnest P. J. Phys. Chem 1996;100:468.

5. Dabbousi RO, Rodriguez-Viejo J, Mikulec FV, Heine JR, Mattoussi H, Ober R, Jensen KF, Bawendi MG. J Phys Chem B 1997;101:9463. 
6. Tsay JM, Pflughoefft M, Bentolila LA, Weiss S. J. Am. Chem. Soc 2004;126:1926. [PubMed: 14971912]

7. Bruchez M, Moronne M, Gin P, Weiss S, Alivisatos AP. Science 1998;281:2013. [PubMed: 9748157]

8. Gerion D, Pinaud F, Williams SC, Parak WJ, Zanchet D, Weiss S, Alivisatos AP. J Phys Chem B 2001;105:8861.

9. Chan WCW, Nie SM. Science 1998;281:2016. [PubMed: 9748158]

10. Guo W, Li JJ, Wang YA, Peng X. J. Am. Chem. Soc 2003;125:3901. [PubMed: 12656625]

11. Larson DR, Zipfel WR, Williams RM, Clark SW, Bruchez MP, Wise FW, Webb WW. Science 2003;300:1434. [PubMed: 12775841]

12. Dubertret B, Skourides P, Norris DJ, Noireaux V, Brivanlou AH, Libchaber A. Science 2002;298:1759. [PubMed: 12459582]

13. Mattoussi H, Mauro JM, Goldman ER, Green TM, Anderson GP, Sundar VC, Bawendi MG. Phys Status Solidi B 2001;224:277.

14. Kim S, Bawendi MG. J. Am. Chem. Soc 2003;125:14652. [PubMed: 14640609]

15. Pinaud F, King D, Moore H, Weiss S. J. Am. Chem. Soc 2004;126:6115. [PubMed: 15137777]

16. Michalet, X.; Doose, S., unpublished results.

17. Manna L, Scher EC, Li LS, Alivisatos AP. J. Am. Chem. Soc 2002;124:7136. [PubMed: 12059239]

18. Murray CB, Norris DJ, Bawendi MG. J. Am. Chem. Soc 1993;115:8706.

19. Peng ZA, Peng XG. J. Am. Chem. Soc 2002;124:3343. [PubMed: 11916419]

20. Li JJ, Wang YA, Guo WZ, Keay JC, Mishima TD, Johnson MB, Peng XG. J. Am. Chem. Soc 2003;125:12567. [PubMed: 14531702]

21. Magde D, Elson EL, Webb WW. Biopolymers 1974;13:29. [PubMed: 4818131]

22. Rigler R, Mets U, Widengren J, Kask P. Eur. Biophys. J 1993;22:169.

23. Doose, $\mathrm{S}$., et al., unpublished results.

24. Ebenstein Y, Mokari T, Banin U. Appl. Phys. Lett 2002;80:4033.

25. Talapin DV, Rogach AL, Kornowski A, Haase M, Weller H. Nano Lett 2001;1:207.

J Phys Chem B. Author manuscript; available in PMC 2005 December 15. 

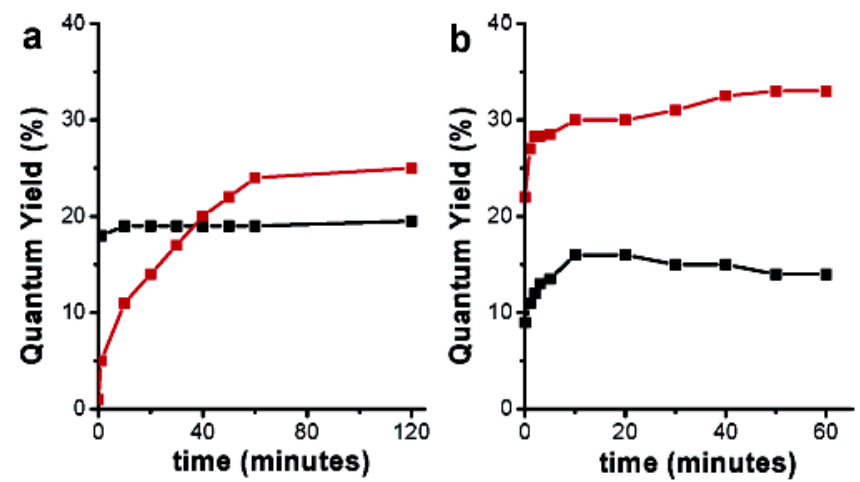

Figure 1.

Effect of UV illumination on QY of typical samples of NCs over time: (a) Sample \#1 (black) and sample \#2 (red) in toluene as synthesized. (b) Sample \#1 (black) and sample \#2 (red) in water (with peptides). 

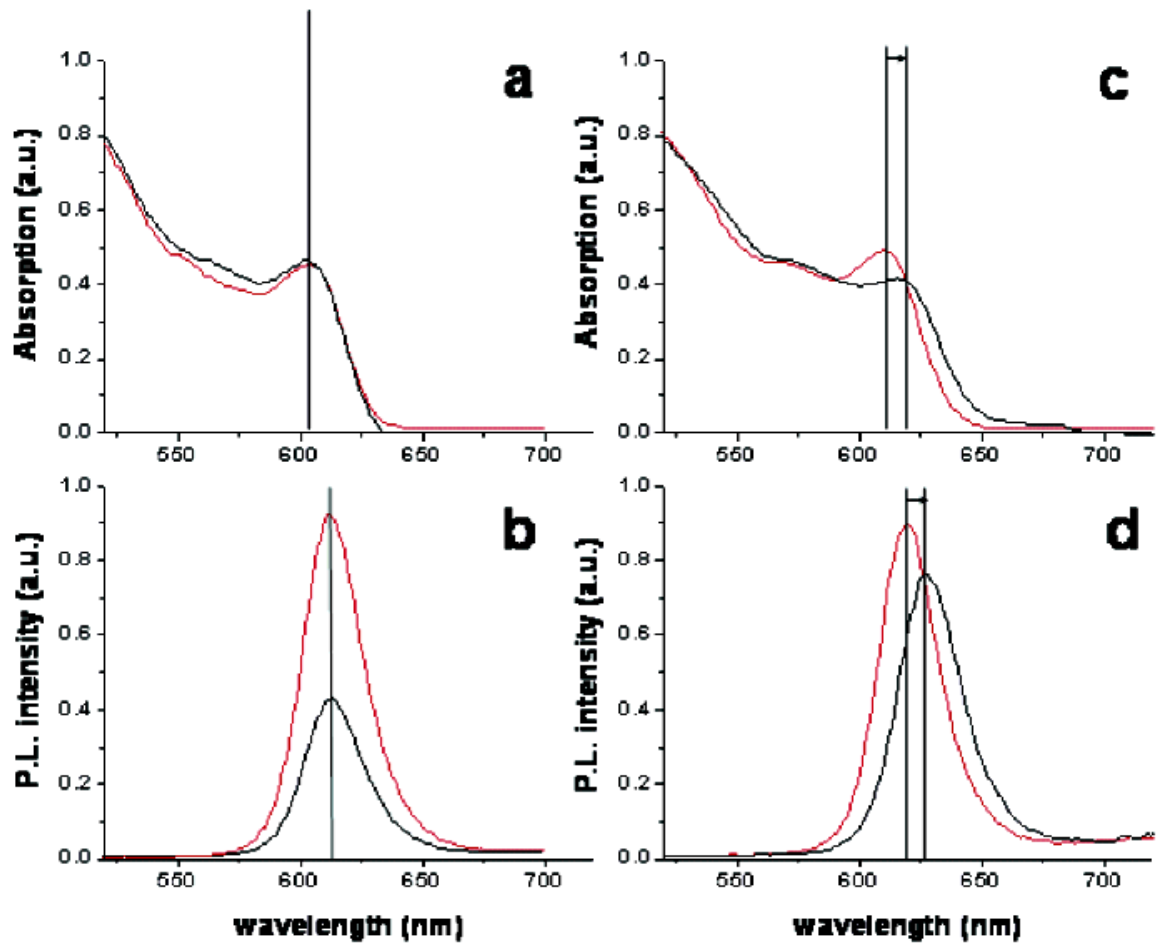

Figure 2.

(a) UV/vis absorption and (c) emission spectra of TBP/TOPO CdSe/ZnS NCs in toluene (red) and with peptides in water (black) normalized to the same OD. (b) UV/vis absorption and (d) emission spectra of TBP/TOPO CdSe/CdZnS NCs NCs in toluene (black) and with peptides in water (red) normalized to the same OD. 

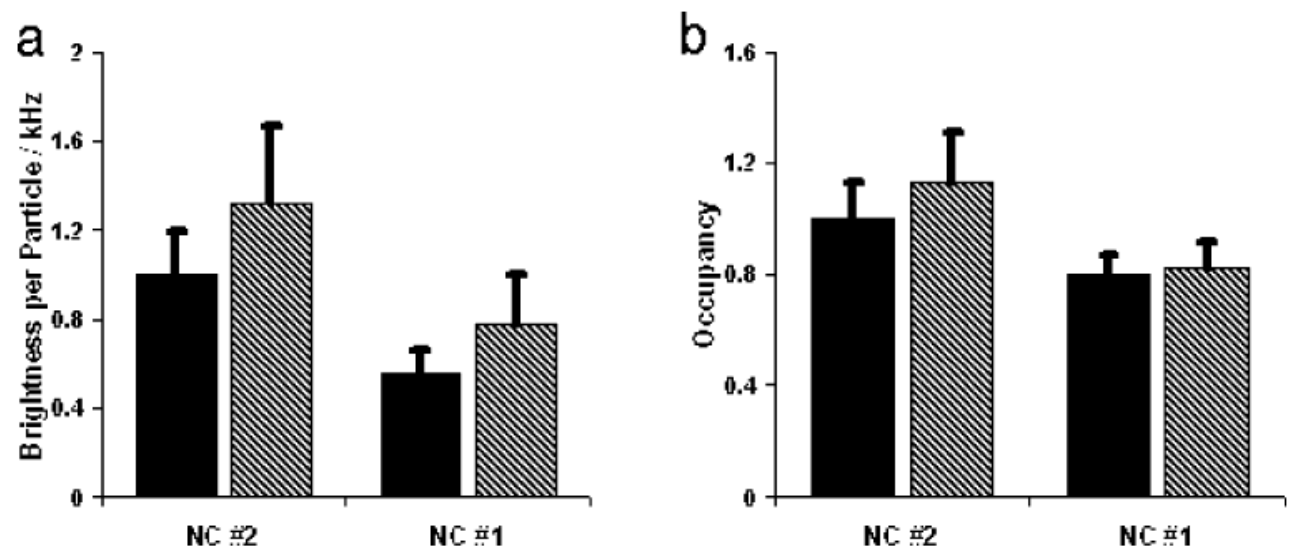

Figure 3.

(a) Brightness per particle of $\mathrm{CdSe} / \mathrm{ZnS}$ (sample \#1) and CdSe/CdS/ZnS (\#2) before (black) and after (hatched) 40 min of UV illumination. (b) Occupancy of fluorescent NCs before (black) and after (hatched) illumination. Values of occupancy are relative to NC\#2 without UV illumination (set as 1). 

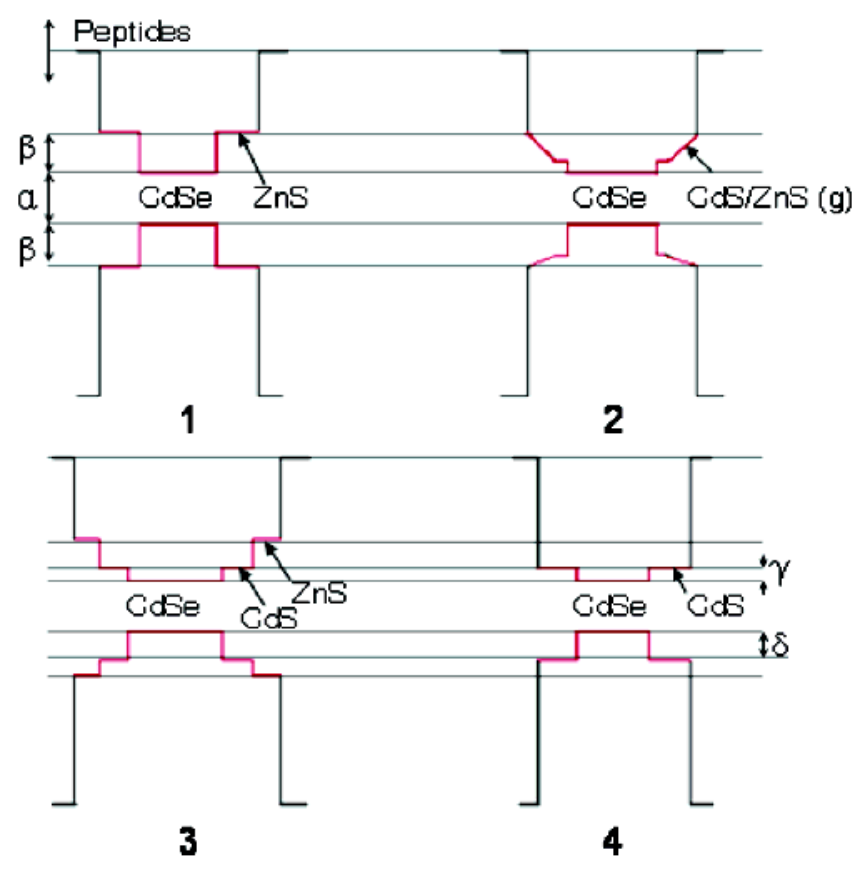

Figure 4.

Approximate values for band offsets of core/shell NCs (1-4) synthesized in these experiments. These values are approximated from this study as $\alpha=2.05-2.15 \mathrm{eV}$ and are taken from ref 5 as $\beta=0.90 \mathrm{eV}, \gamma=0.20 \mathrm{eV}$, and $\delta=0.55 \mathrm{eV}$. 
TABLE 1

CdSe Cores Overcoated with Inorganic Shells of Various Compositions at Different Stages of Peptide Exchange $^{a}$

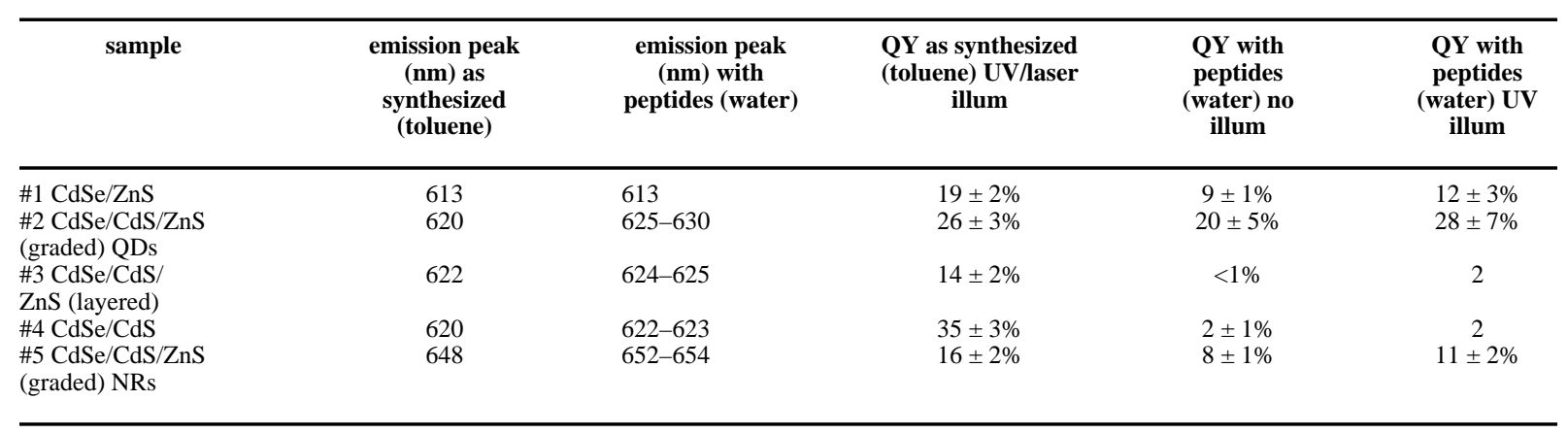

${ }^{a}$ All quantum dots (\#1-4) have identical core sizes (4.5 nm) except for sample \#4 (CdSe/CdS, $3.5 \mathrm{~nm}$ core). Sample \#5 has a $5 \times 25 \mathrm{~nm}$ core. 